\title{
An unusual presentation of atrial myxoma
}

\author{
Shaemala Anpalakhan ${ }^{1}$, MBChB, Dewi Ramasamy ${ }^{2}$, MBBS, Kin Sing $\underline{\text { Fan }}^{3}$, MBBS
}

ABSTRACT Myxomas are uncommon primary cardiac tumours that usually affect the left atrium. We herein report the case of a patient who presented with right heart failure and proteinuria, leading to the diagnosis of atrial myxoma. Surgical resection resulted in resolution of the patient's symptoms.

Keywords: atrial myxoma, heart failure, proteinuria

\section{INTRODUCTION}

An atrial myxoma is a rare benign cardiac tumour, commonly occurring within the left atrium. ${ }^{(1)}$ It has a prevalence of less than 5 out of every 10,000, and a female to male ratio of 2:1. . $^{(1,2)}$ The mean age of patients with atrial myxoma is reported to be 56 years for sporadic cases and 25 years for familial cases. ${ }^{(1,2)}$ Its typical triad of presentation comprises tumour embolism, blood flow obstruction and constitutional symptoms. ${ }^{(3)}$ We herein report a case of an unusual presentation of atrial myxoma in a patient with right heart failure and proteinuria.

\section{CASE REPORT}

A previously healthy 28-year-old woman presented to her general practitioner (GP) with a two-week history of nonproductive cough. Examination of her respiratory and cardiovascular systems showed no abnormalities. As her cough did not resolve, she returned to her GP a month later, this time complaining also of bilateral leg swelling. To investigate a possible renal aetiology, a urine dipstick test was carried out and the resulting score of $3+$ suggested only proteinuria. The patient, however, did not describe any urinary symptoms such as haematuria. The finding of proteinuria, together with leg swelling, prompted referral to a nephrologist.

Formal urinalysis confirmed the occurrence of proteinuria (protein concentration $500 \mathrm{mg} / \mathrm{dL}$ ). Chest radiography showed congested lung fields with a cardiothoracic ratio of $1: 2$. Physical examination revealed a thin patient who was not jaundiced or cyanosed. Her heart pulse was regular at $100 \mathrm{bpm}$, blood pressure was 90/60 mmHg and jugular venous pressure was elevated. A soft mid-diastolic murmur with a loud second heart sound was heard. Her lungs had bibasilar crackles with mildly decreased air entry in the right base. There was a mild degree of ascites and the liver edge was palpable.

Upon further questioning, the patient described a two-week history of effort dyspnoea, paroxysmal nocturnal dyspnoea and orthopnoea prior to the nephrologist's assessment. She had no past medical or drug history, was a nonsmoker and did not consume alcohol. To rule out a myocarditis-like cause prior to a renal biopsy, cardiology review and echocardiography were performed.
Table I. Blood test results of the patient.

\begin{tabular}{|c|c|c|c|}
\hline Parameter & $\begin{array}{l}\text { Normal } \\
\text { range* }\end{array}$ & Preoperation & Postoperation \\
\hline Haemoglobin (g/dL) & $12.0-16.0$ & 12.8 & 12.4 \\
\hline Platelets $\left(10^{9} / \mathrm{L}\right)$ & $150-400$ & 477 & 390 \\
\hline WCC $\left(10^{9} / \mathrm{L}\right)$ & $4-11$ & 9.6 & 10.0 \\
\hline $\mathrm{ESR}(\mathrm{mm} / \mathrm{hr})$ & $0-20$ & 5 & 6 \\
\hline Total protein $(\mathrm{g} / \mathrm{L})$ & $60-83$ & 54 & 72 \\
\hline Albumin $(\mathrm{g} / \mathrm{L})$ & $35-50$ & 27 & 38 \\
\hline Bilirubin $(\mu \mathrm{mol} / \mathrm{L})$ & $0-26.1$ & 15.5 & 14.3 \\
\hline $\operatorname{ALP}(U / L)$ & $50-136$ & 93 & 90 \\
\hline $\operatorname{ALT}(U / L)$ & $30-65$ & 57 & 50 \\
\hline GGT (U/L) & $5-55$ & 40 & 42 \\
\hline Sodium (mmol/L) & $139-149$ & 140 & 140 \\
\hline Potassium (mmol/L) & $3.6-5.2$ & 4.8 & 4.6 \\
\hline Urea (mmol/L) & $3-8$ & 6.4 & 5.0 \\
\hline Creatinine $(\mathrm{mmol} / \mathrm{L})$ & $40-120$ & 81 & 70 \\
\hline Glucose $(\mathrm{mmol} / \mathrm{L})$ & $3.9-5.5$ & 5.1 & - \\
\hline $\begin{array}{l}\text { Complement } 3 \\
(\mathrm{mmol} / \mathrm{L})\end{array}$ & $0.90-2.07$ & 1.24 & - \\
\hline $\begin{array}{l}\text { Total cholesterol } \\
(\mathrm{mmol} / \mathrm{L})\end{array}$ & $<5.2$ & 3.6 & - \\
\hline $\begin{array}{l}\text { Urinalysis protein } \\
(\mathrm{mg} / \mathrm{dL})\end{array}$ & - & 500 & 9 \\
\hline
\end{tabular}

*Values obtained from the hospital's laboratory. †At six weeks post operation. ALT: alanine aminotransferase; ALP: alkaline phosphatase; GGT: gamma-glutamyl transpeptidase; ESR: erythrocyte sedimentation rate; WCC: white cell count

Blood test results revealed mildly elevated platelet count, normal erythrocyte sedimentation rate and hypoalbuminaemia (Table I). Her renal function was also normal. Electrocardiography (ECG) showed sinus rhythm and P mitrale, while two-dimensional echocardiography revealed a large left atrial myxoma prolapsing through the mitral valve and into the left ventricle (Figs. $1 \& 2$ ). There was mild pericardial effusion, and the chambers on the right side of the heart were enlarged with severe tricuspid regurgitation. Pulmonary artery pressure was $65 \mathrm{mmHg}$ and the ejection fraction was $50 \%$.

Given the unexpected findings, the patient was referred to a cardiothoracic surgeon, and removal of the atrial myxoma

${ }^{1}$ Department of Internal Medicine, Aberdeen Royal Infirmary, Aberdeen, United Kingdom, ${ }^{2}$ Department of Cardiology, ${ }^{3}$ Department of Nephrology, Gleneagles Intan Hospital, Kuala Lumpur, Malaysia

Correspondence: Dr Dewi Ramasamy, Consultant Cardiologist, Department of Cardiology, Gleneagles Intan Hospital, Kuala Lumpur 50450, Malaysia dewiramasamy@hotmail.com 
and atrial septectomy were performed. The gelatinous mass $(6 \mathrm{~cm} \times 4 \mathrm{~cm} \times 2.5 \mathrm{~cm})$ was attached to the middle of the interatrial septum on the left atrial side of the fossa ovalis. Histology revealed a polypoid lesion composed of stellate cells in a myxoid vascular stroma, with no atypia or mitosis seen, in keeping with a benign atrial myxoma. The tricuspid valve was structurally normal.

At six weeks post operation, the patient was categorised as Class I, according to the New York Heart Association (NYHA) functional classification. ${ }^{(4)}$ Repeat ECG showed no residual myxoma, mild tricuspid regurgitation, a pulmonary artery pressure of $45 \mathrm{mmHg}$, and good left ventricular function (Fig. 3). Repeat urinalysis revealed a protein concentration of $9 \mathrm{mg} / \mathrm{dL}$, which confirmed the resolution of proteinuria in the patient.

\section{DISCUSSION}

This report describes an atrial myxoma in a patient with right heart failure and proteinuria, whose signs and symptoms resolved after surgery. This case is unusual in terms of its presentation, leading to the unexpected finding of an atrial myxoma.

Proteinuria is defined as the urinary excretion of proteins. In urine dipstick tests, a score of $3+$ can mean a proteinuria range of $300-1,000 \mathrm{mg} /$ day.$^{(5)}$ Overt proteinuria occurs when the total protein in urine is $>300 \mathrm{mg} /$ day, while nephroticrange proteinuria develops when the total protein in urine is $>350 \mathrm{mg} /$ day. ${ }^{(5)}$ Nephrotic-range proteinuria, coupled with peripheral oedema, hypoalbuminaemia and hyperlipidaemia, suggests nephrotic syndrome. ${ }^{(5)}$ In general, the more severe the proteinuria, the more likely it is that the condition is of renal aetiology. Microalbuminuria may also be seen in patients with heart failure, and this manifestation is thought to be due to altered glomerular perfusion. ${ }^{(6)}$

Atrial myxoma, which occurs most commonly within the left atrium, frequently develops with symptoms of tumour embolism, obstruction and/or constitutional symptoms. Leo et al reported that a myxoma in the left atrium region may mimic mitral stenosis, ${ }^{(7)}$ and if left undetected, may lead to the development of left atrial enlargement, as seen in our patient, and right heart failure, a phenomenon previously described as occurring in about $4 \%$ of cases. ${ }^{(8)}$ This would have contributed to the development of peripheral oedema, as seen in our patient. However, with regard to the degree of proteinuria seen in cases of heart failure, the condition tends to be microalbuminuria rather than gross proteinuria, as demonstrated in our patient.

In terms of the association between atrial myxomas and proteinuria, there have only been two previously published cases of patients with atrial myxomas presenting with proteinuria. The first report, like ours, described a patient with right-sided heart failure presenting with proteinuria, without evidence of renal pathology. ${ }^{(9)}$ The second paper reported a patient with proteinuria and haematuria but without any other symptoms. ${ }^{(10)}$ Both papers described complete resolution of the patients' symptoms following surgery.

We believe that a renal biopsy was not justified in our case, as the patient had not presented with any other urinary abnormalities aside from proteinuria, which resolved following surgical excision

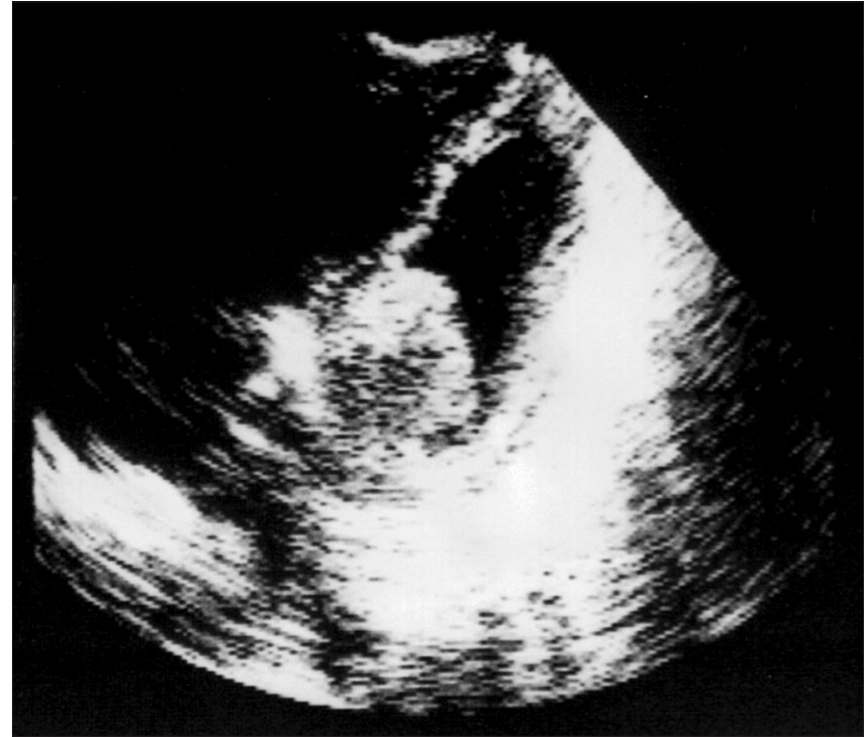

Fig. 1 Four-chamber view echocardiogram shows the myxoma attached to the interatrial septum.

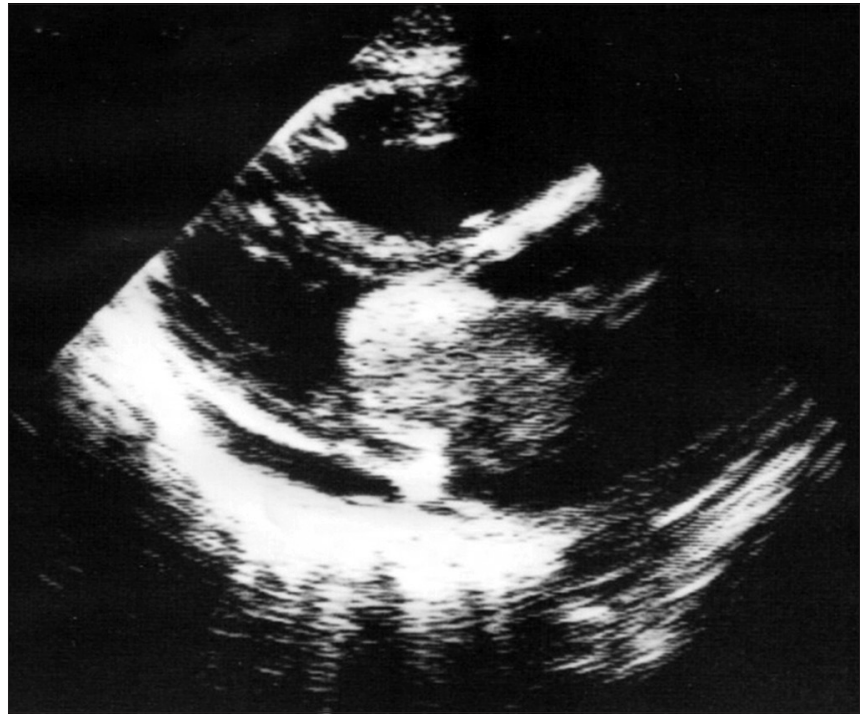

Fig. 2 Long-axis view echocardiogram shows the myxoma prolapsing through the mitral valve.

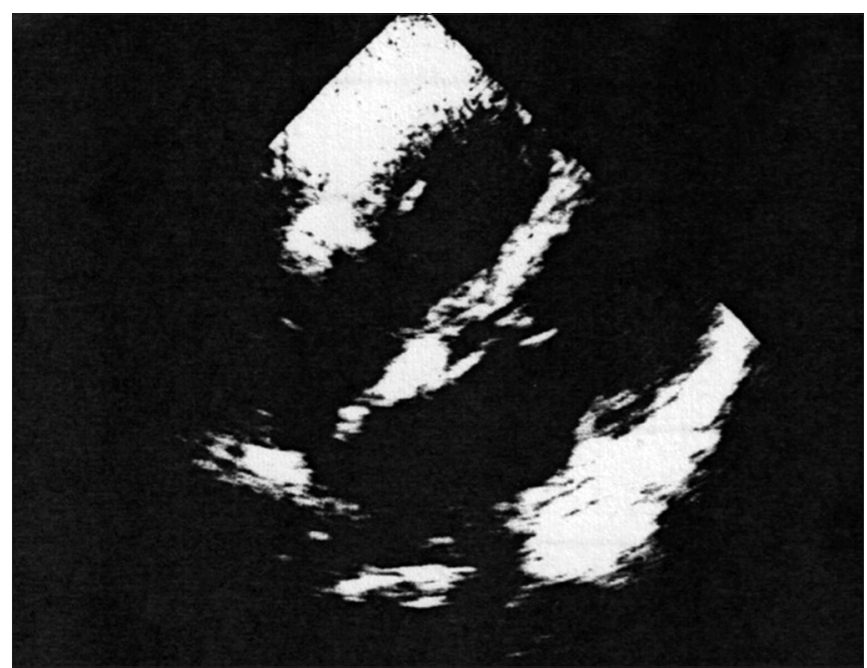

Fig. 3 Post-surgery four-chamber view echocardiogram shows no residual myxoma, mild tricuspid regurgitation, a pulmonary artery pressure of $45 \mathrm{mmHg}$, and good left ventricular function. 
of the atrial myxoma. The resolution of proteinuria suggests that atrial myxomas may have a direct role in such urinary abnormalities. It has been previously described that myxomas produce interleukin- 6 and anti-endothelial cell antibodies, which may have a role in disrupting normal glomerular function, leading to proteinuria. ${ }^{(10)}$

The clinical lesson highlighted in this report is the importance of including atrial myxomas in the differential diagnosis when investigating abnormalities detected by urinalysis. In countries where the detection rates of cardiac abnormalities are low, it is important to consider atrial myxoma as a differential factor. As surgical resection appears to result in the resolution of signs and symptoms, a high index of clinical suspicion is necessary to aid in a prompt diagnosis and management.

\section{REFERENCES}

1. Aggarwal SK, Barik R, Sarma TC, et al. Clinical presentation and investigation findings in cardiac myxomas: new insights from the developing world. Am Heart J 2007; 154:1102-7.
2. Larsson S, Lepore V, Kennergren C. Atrial myxomas: results of 25 years' experience and review of the literature. Surgery 1989; 105:695-8.

3. Pinede L, Duhaut $P$, Loire R. Clinical presentation of left atrial cardiac myxoma. A series of 112 consecutive cases. Medicine (Baltimore) 2001; 80:159-72.

4. The Criteria Committee of the New York Heart Association. Nomenclature and Criteria for Diagnosis of Diseases of the Heart and Great Vessels. 9th ed. Boston: Little, Brown \& Co, 1994: 253-6.

5. Sperati JC, Fine DM. Assessment of proteinuria [Online]. Available at: http://bestpractice.bmj.com/best-practice/monograph/875.html. Accessed August 10, 2013.

6. Peeroo K, Clark A. The prevalence of proteinuria in patients presenting with fluid retention due to heart failure. J R Coll Physicians Edinb 2010; 40:301-3.

7. Leo S, Yang K, Weng C, Liang Z. Large atrial myxoma mimicking severe mitral stenosis associated with right heart enlargement and severe pulmonary hypertension. Cardiovasc Diagn Ther 2013; 3:52-4.

8. Oliveira R, Branco L, Galrinho A, et al. Cardiac myxoma: a 13-year experience in echocardiographic diagnosis. Rev Port Cardiol 2010; 29:1087-100.

9. Kalra PA, Raghavan C, Hassan R, Lawson R, Waldek S. Nephrotic-range proteinuria associated with right atrial myxoma. Clin Nephrol 1992; 37:294-6.

10. Bushnell JR, Weston C, Karamadoukis L. An unusual presentation of atrial myxoma with hematuria and proteinuria. NDT Plus 2011; 4:124-5. 